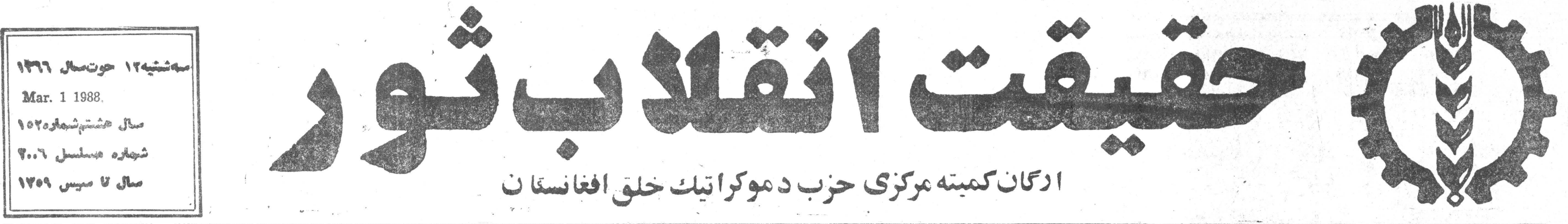

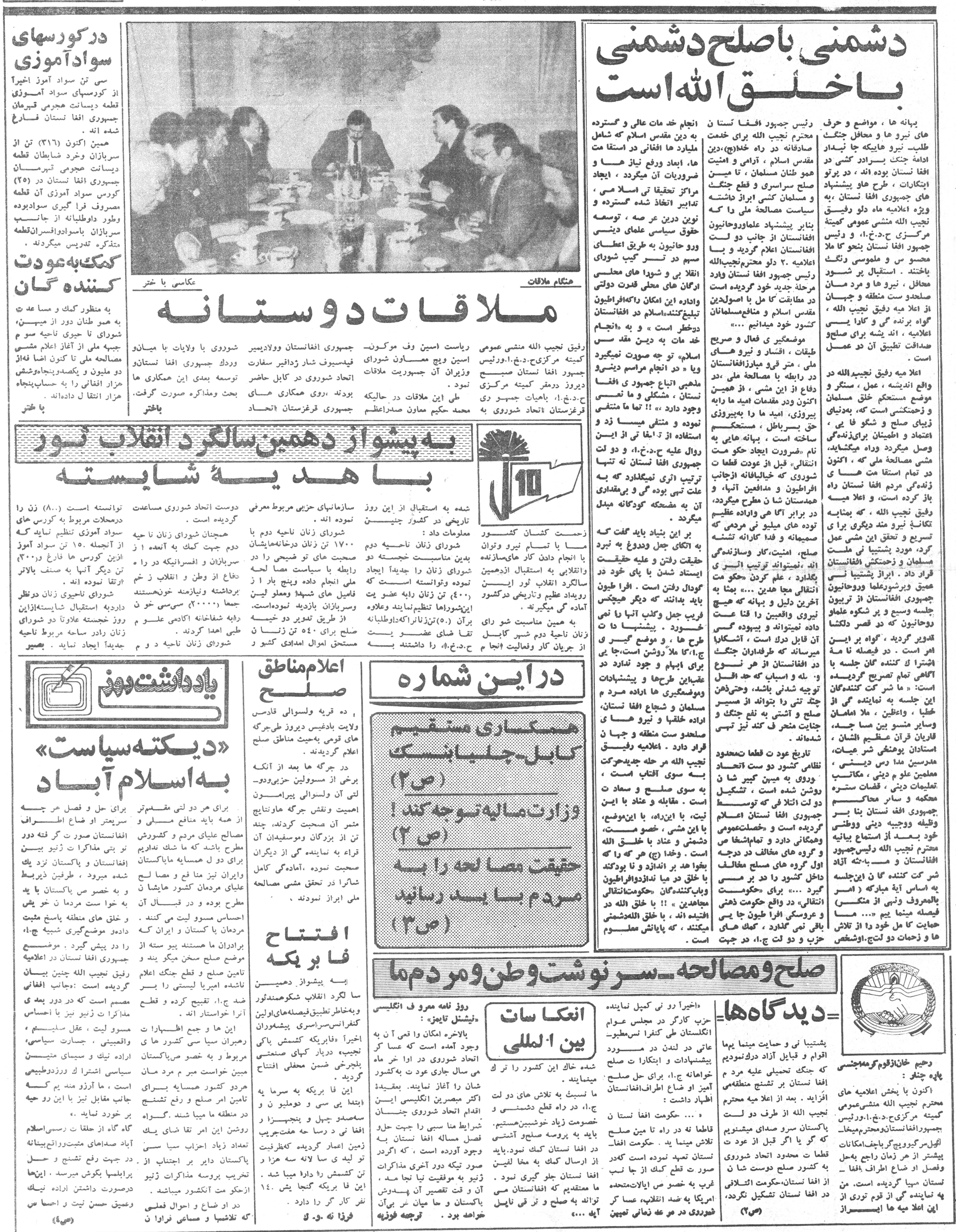


ว و

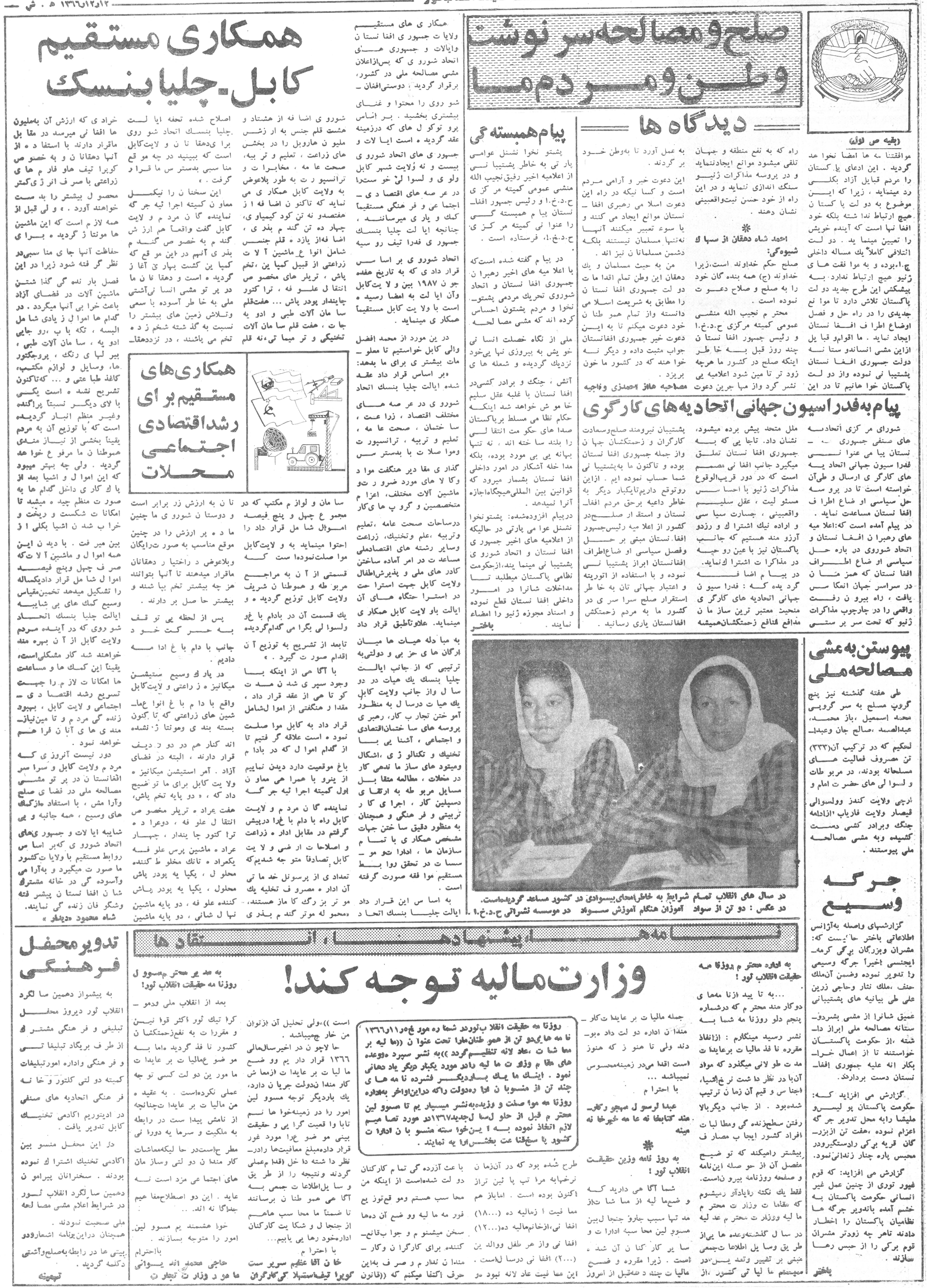




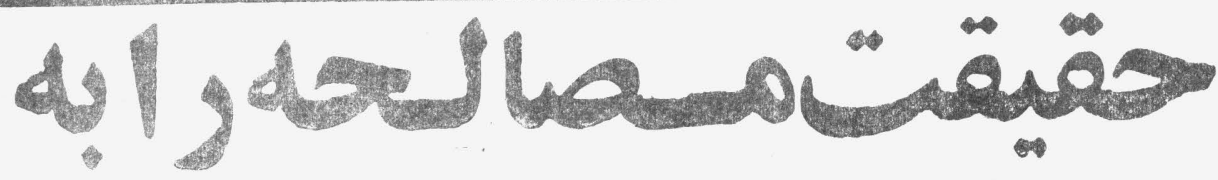

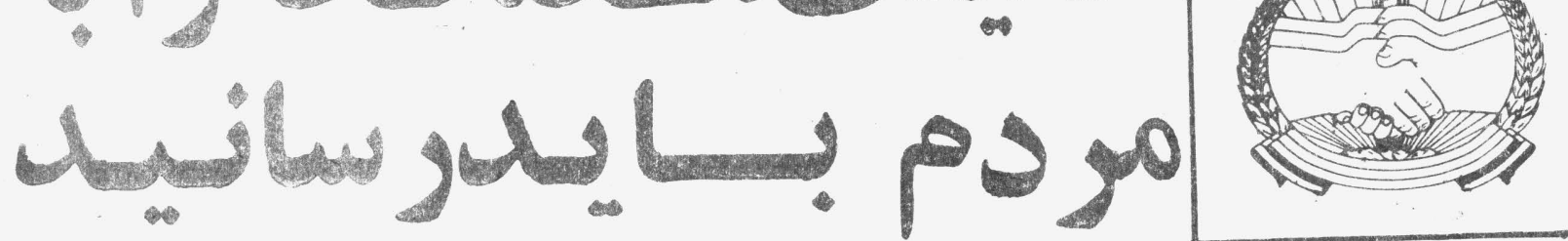

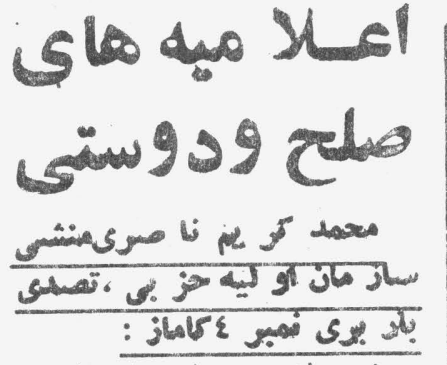
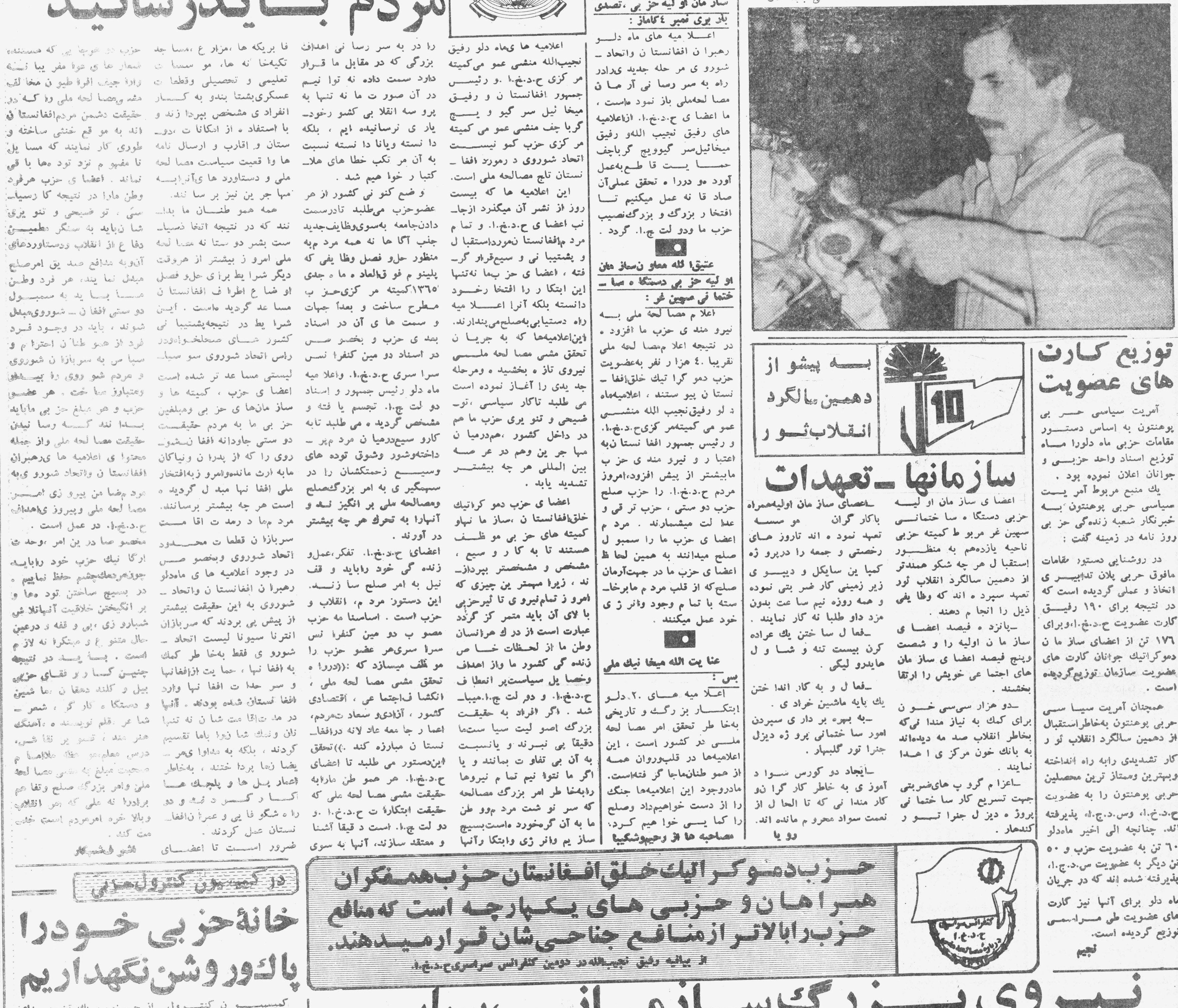

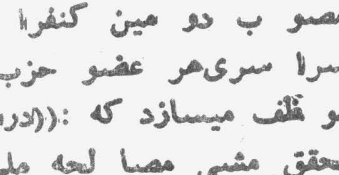

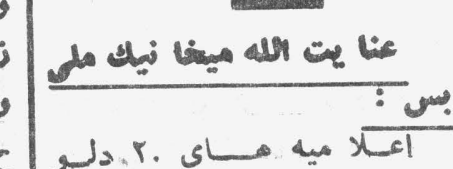

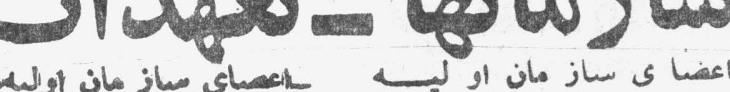
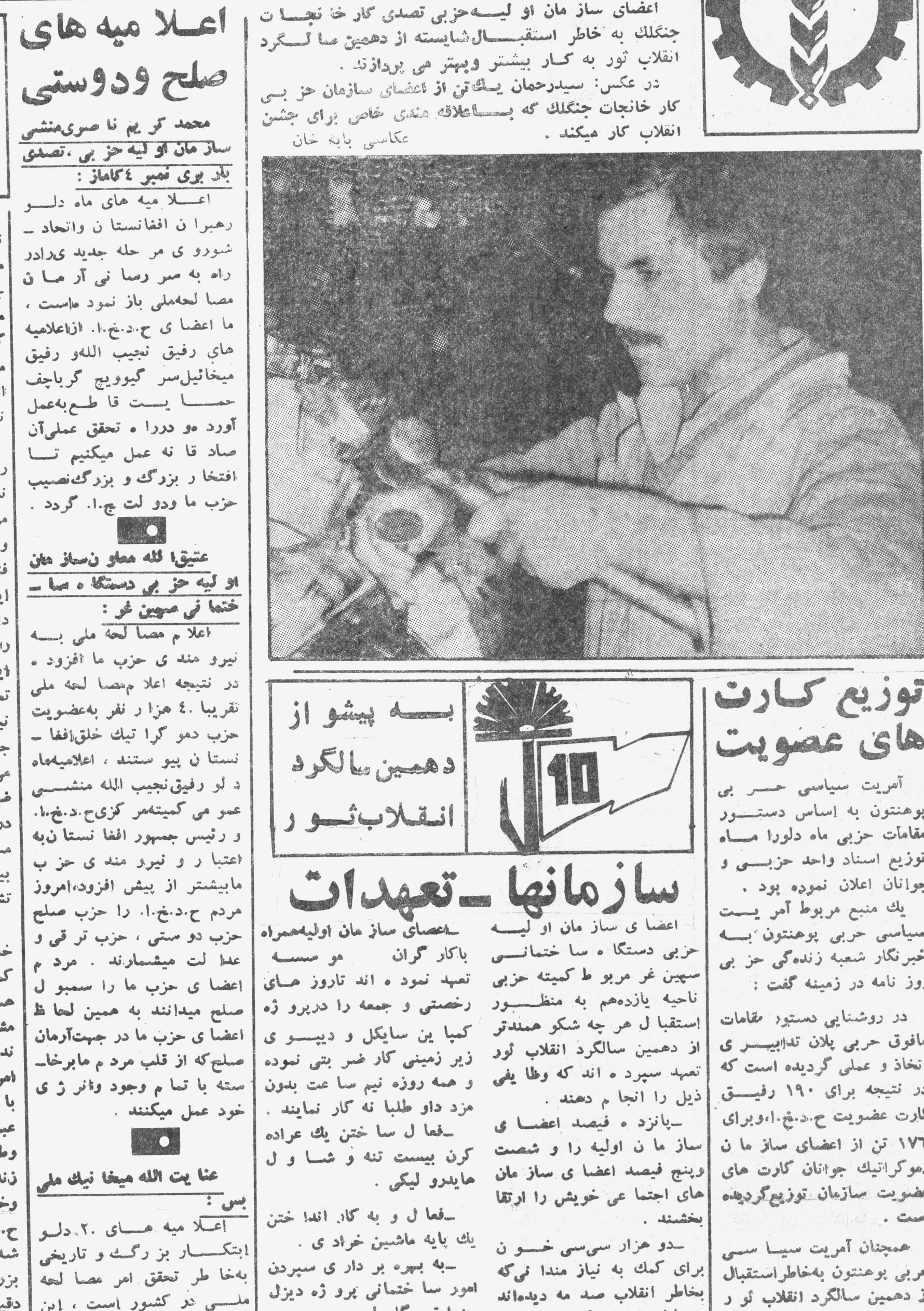

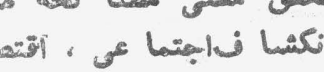

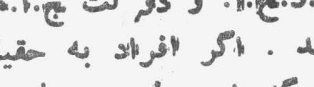

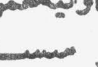

نا

con

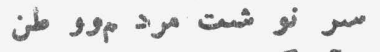

四

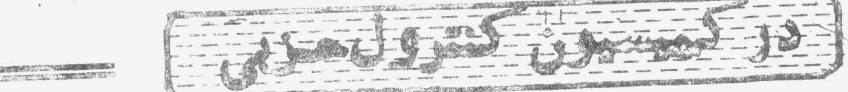
$23 \rightarrow 5.3015$

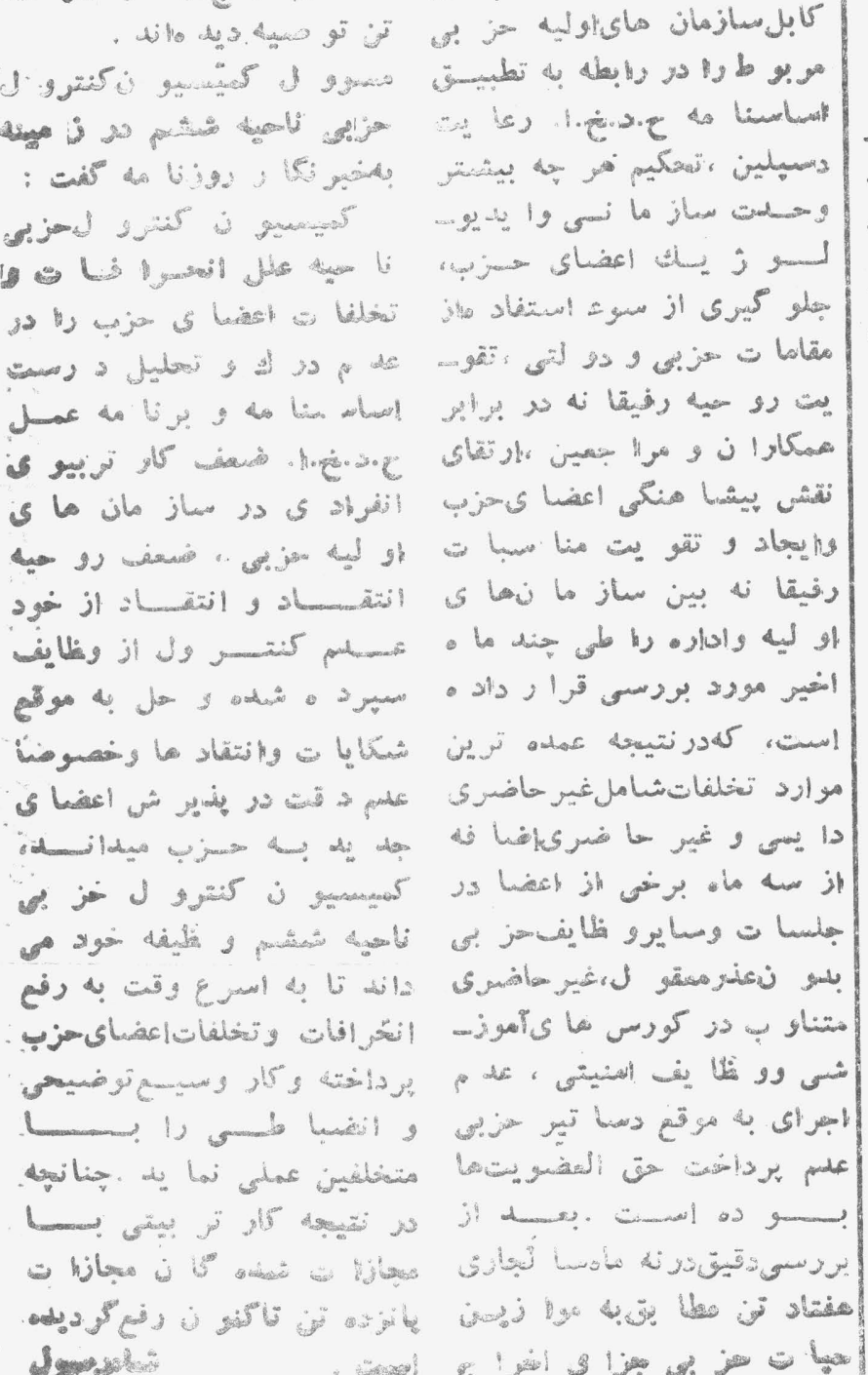

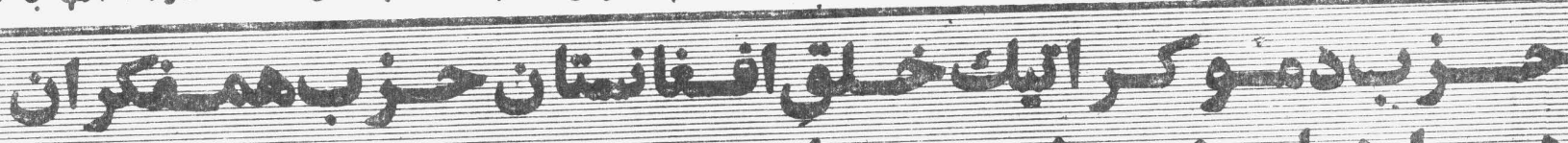

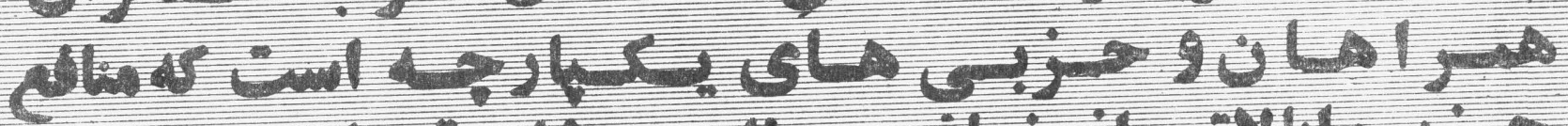

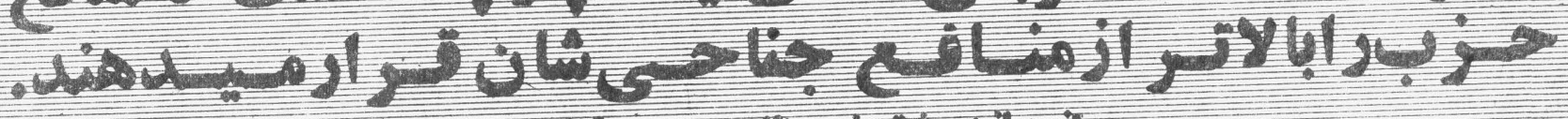

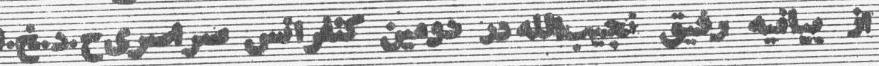

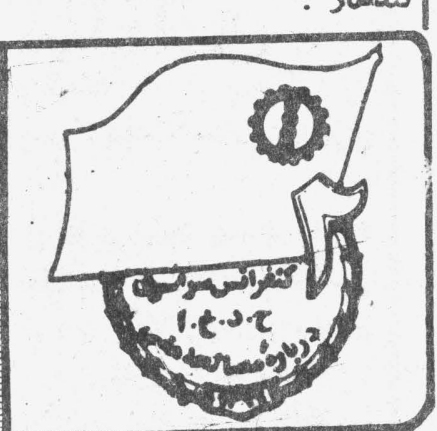

a.

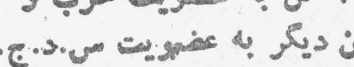

مان

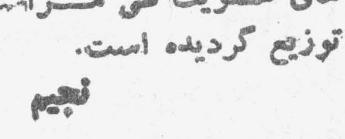

\section{ك 59} ग1

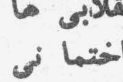

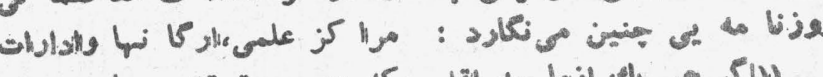

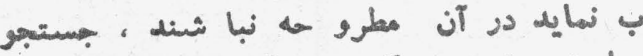

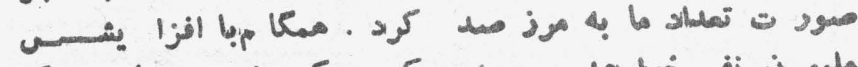

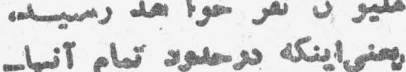

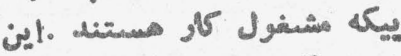

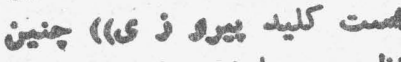

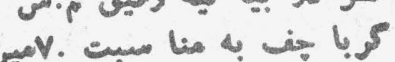

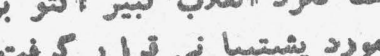

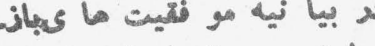

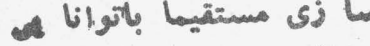

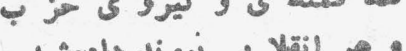
بو

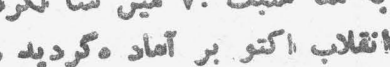

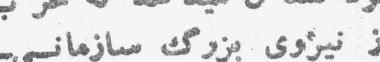

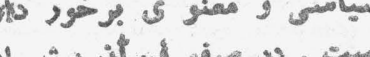

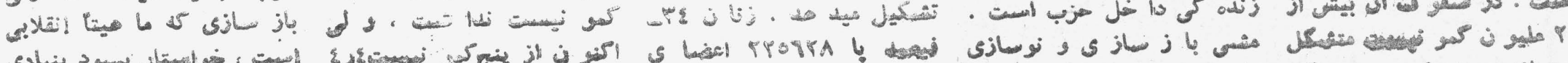

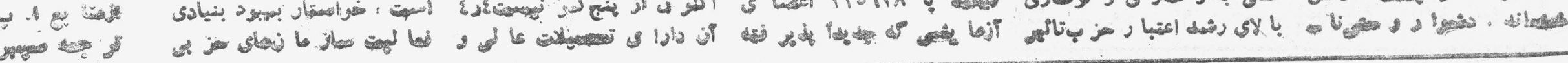




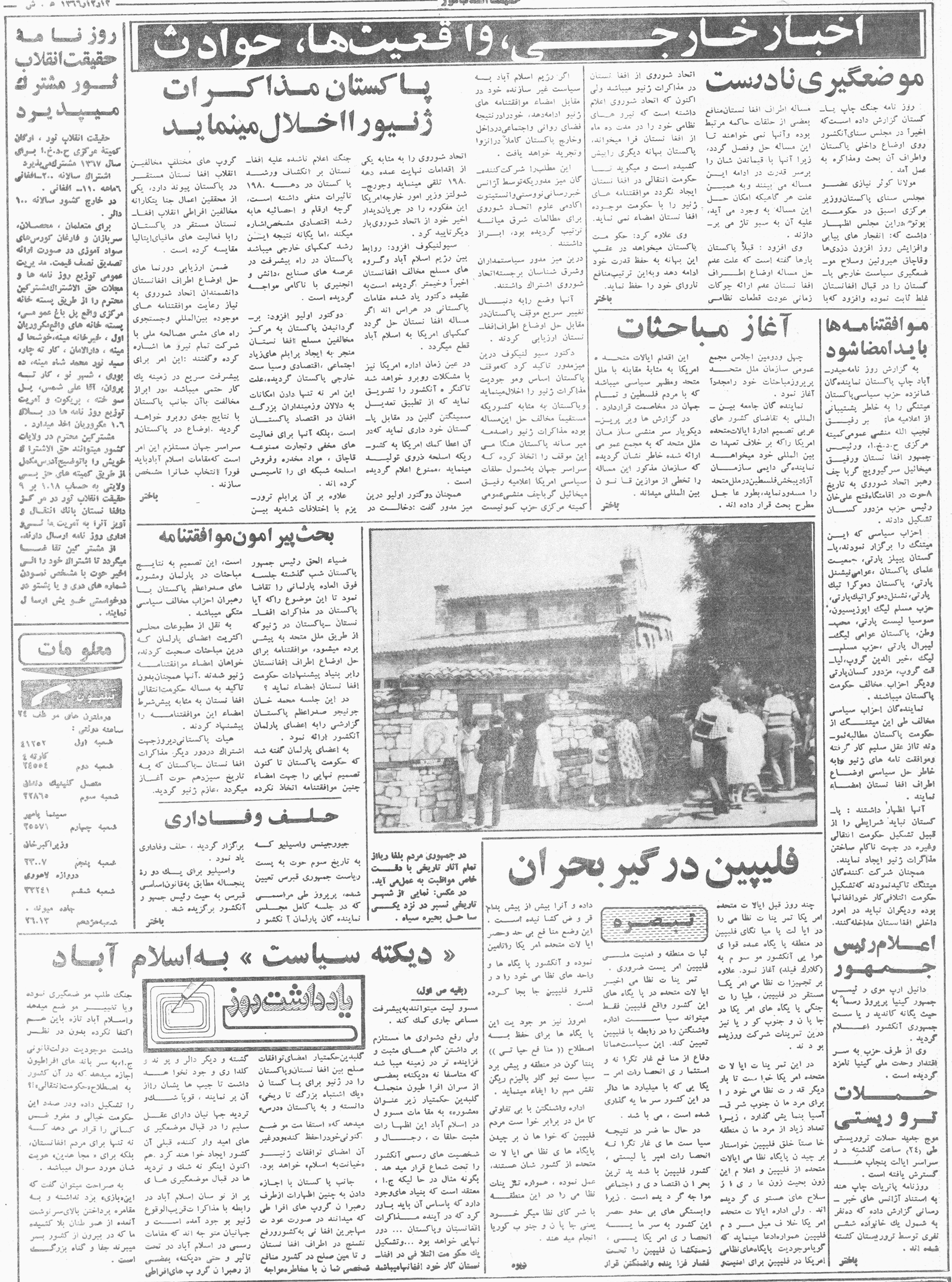

